\title{
Effectiveness of Benson's Relaxation Therapy on Reduction of Postcesarean Pain and Stress among Mothers in a Selected Hospital at Kochi
}

\author{
Soumya Raj $K^{1}$, Rakhi R Pillai ${ }^{2}$
}

\begin{abstract}
Pain and stress presented in postcesarean mothers make the recovery hard, and it affects the mother's connection with the newborns. Benson's relaxation therapy is a simple practice that can help to relieve pain and stress.

Aim of the study: Main aim is to evaluate the effectiveness of Benson's relaxation therapy in pain and stress among postcesarean mothers between the experimental and control groups.

Methodology: In this study, researchers used quasi-experimental design with pretest \pm posttest control group design. The setting of the study was Amrita Hospital, Kochi. A sample of 60 postcesarean mothers ( 30 in each group) were selected by using the convenient sampling technique. Result: Present study reveals a significant difference between pretest and posttest stress and pain in the experimental group, which is statistically significant with $p$-value $<0.05$. In the control group, pretest stress and posttest stress were not significantly different and there is a difference in pretest and posttest pain scores as $p$-value is $<0.05$. When comparing percentage distribution of posttest pain in both groups, majority of experimental group (76.7\%) had mild pain and $23.3 \%$ of them had moderate pain. On the contrary, in the control group, only $16.7 \%$ of the postcesarean mothers had mild pain and about $50 \%$ had moderate pain, and $33.3 \%$ had severe pain.

Conclusion: Benson's relaxation therapy can use effectively by the midwife for a significant reduction in pain and stress among postcesarean mothers.

Keywords: Benson's relaxation therapy, Effectiveness, Postcesarean mother, Postcesarean pain, Postcesarean stress.

Journal of South Asian Federation of Obstetrics and Gynaecology (2021): 10.5005/jp-journals-10006-1875
\end{abstract}

\section{INTRODUCTION}

Cesarean section is an operative procedure where by the fetus after the end of 28 th week is delivered through an incision on the abdomen and uterine walls. Incidence is steadily rising. During the last decade, there have been two- to three-fold rises in incidence from the initial rate of about $10 \%$.

Surgery threatens the integrity of the body, such as biopsychosocial-spiritual aspects, and may cause discomfort, such as pain response. Experience of pain is associated with many immediate and long-term negative outcomes. ${ }^{2}$

Recently, many methods being developed to address the problem of pain in women with severe postcesarean section pain, either by pharmacological and nonpharmacological approaches. One nonpharmacological way suitable to reduce pain intensity is relaxation. Relaxation aims to reduce anxiety, decrease muscle tension and bone, and indirectly relieve pain and reduce tension related to the body's physiological status. ${ }^{3}$

Postnatal mothers are suffering from perceived postpartum stress in attaining maternal roles, dealing with negative body changes, and in lack of social support. ${ }^{4}$ Women are faced with various life stressors, including menstrual problems, comorbidities, and marriage. ${ }^{5}$

Childbirth is being a joyous event, at the same time, it is a time of pain, fear, and stress. Stress is a part of human life, and we are never completely free from stress. Stress in one area can lead to stress in another. Many things in our life can be stressful, such as period of development, marriage, childbirth, etc. ${ }^{6}$
${ }^{1}$ Department of Obstetrics and Gynecological Nursing, Amrita College of Nursing, Amrita Vishwa Vidhyapeetham, Health Sciences Campus, Kochi, Kerala, India

${ }^{2}$ Amrita College of Nursing, Amrita Vishwa Vidhyapeetham, Health Sciences Campus, Kochi, Kerala, India

Corresponding Author: Soumya Raj K, Department of OBG Nursing, Amrita College of Nursing, Amrita Vishwa Vidhyapeetham, Health Sciences Campus, Kerala, India, Phone: +91 9895726750, e-mail: soumyarajk@gmail.com

How to cite this article: Raj SK, Pillai RR. Effectiveness of Benson's Relaxation Therapy on Reduction of Postcesarean Pain and Stress among Mothers in a Selected Hospital at Kochi. J South Asian Feder Obst Gynae 2021;13(2):121-124.

Source of support: Nil

Conflict of interest: None

Benson's relaxation therapy is a technique, which includes deep relaxation, slowed heartbeat and breathing, reduced oxygen consumption, and increased skin resistance. It is around 20 minutes when practiced. ${ }^{7}$

\section{Materials and Methods}

Quasi-experimental design ${ }^{8}$ with pretest \pm posttest control group design was adopted for this study. The research setting was a postnatal ward of Amrita Hospital. A sample of 30 experimental and 30 control groups of postcesarean mothers by using convenient sampling technique was selected for the study. Data collection was done with

( ) Jaypee Brothers Medical Publishers. 2021 Open Access This article is distributed under the terms of the Creative Commons Attribution 4.0 International License (https://creativecommons.org/licenses/by-nc/4.0/), which permits unrestricted use, distribution, and non-commercial reproduction in any medium, provided you give appropriate credit to the original author(s) and the source, provide a link to the Creative Commons license, and indicate if changes were made. The Creative Commons Public Domain Dedication waiver (http://creativecommons.org/publicdomain/zero/1.0/) applies to the data made available in this article, unless otherwise stated. 
the help of tools such as self-administered demographic tool including 12 questions based on age, education, occupation of the mother, occupation of father, type of family, monthly income, the reason for cesarean section, previous knowledge of parenthood classes, exposure to yoga, and social support. To assess the pain level after cesarean section standardized numerical pain rating scale was used which ranges from 0 to 10, as it is a subjective type of tool, women were told to express or rate their pain sensation where " 0 " denotes no pain and " 10 " denotes severe pain. The tool used to assess the stress level was a standardized Hung's stress scale. It is a Likert scale having 62 questions. It is also a type of subjective questionnaire in which each question has ratings that apparently analyze the stress of the woman according to the situation, it ranges from 1 to 5 where 1 denotes "never" and 5 denotes "always." The test was conducted in two phases, i.e., pretest and posttest. For the experimental group, pretest was conducted on first postoperative day and then Benson's relaxation therapy was taught to the mother and it was performed for three times a day upto 20 minutes then posttest was conducted on the fifth postoperative day to assess the effectiveness of Benson's therapy on reduction of pain and stress. For the control group pretest was done on the first postoperative day and posttest was done on the fifth postoperative day. Both groups were getting the usual pharmacological therapy that a patient receives after a cesarean section. Data analysis were performed using descriptive and inferential statistics.

\section{Result}

\section{Section A-Distribution of Postcesarean Mothers According to Their Demographic Variables}

Among the 60 postcesarean mothers, majority (41.7\%) were in the age-group of 30 and above years, and $66.7 \%$ were graduates. Most of them (70\%) were housewives and $50 \%$ are from a nuclear family. About $71.7 \%$ of mothers were living in an urban area and most of them (91.7) have not undergone any yoga classes. More than half of the mothers (53.3\%) had a male child and $90 \%$ of them have not undergone any parenthood classes. $100 \%$ of the samples are getting support from their family especially from their mothers.

\section{Section B-Distribution of Postcesarean Mothers According to Pretest Score on Level of Pain and Stress in Experimental and Control Groups}

In the experimental group of postcesarean mothers, $66.7 \%$ had experienced severe pain and about $33.3 \%$ of the postcesarean mothers had moderate pain, whereas in the control group, majority (73.3\%) of the postcesarean mothers had experienced severe pain and $26.7 \%$ had moderate pain, respectively.

In the experimental group of postcesarean mothers, $16.3 \%$ had experienced severe stress and about $53.3 \%$ of the postcesarean mothers had moderate stress and $33.3 \%$ had mild stress, none of them had eustress and extreme stress. In the control group, $16.7 \%$ of the postcesarean mothers had experienced severe stress, $46.7 \%$ had moderate stress, and $36.7 \%$ had mild stress. In the control group also none of them had eustress and extreme stress which have been shown in Figure 1.

\section{Section C-Distribution of Postcesarean Mothers According to Posttest Score on Level of Pain and Stress in Experimental and Control Groups}

In the experimental group, majority (76.7\%) of the postcesarean mothers had experienced mild pain and about $23.3 \%$ of them

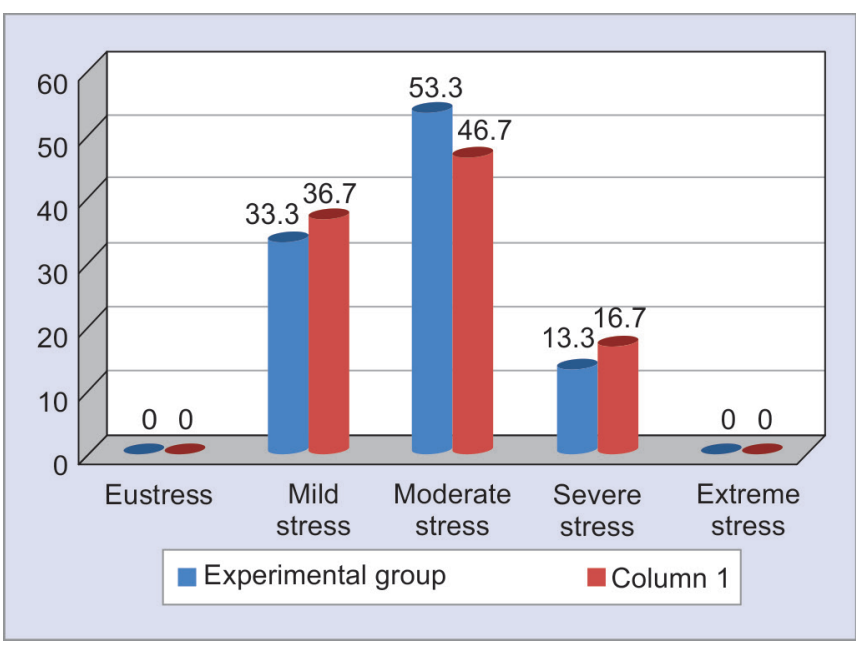

Fig. 1: Distribution of postcesarean mothers according to pretest score on level of stress in experimental and control groups

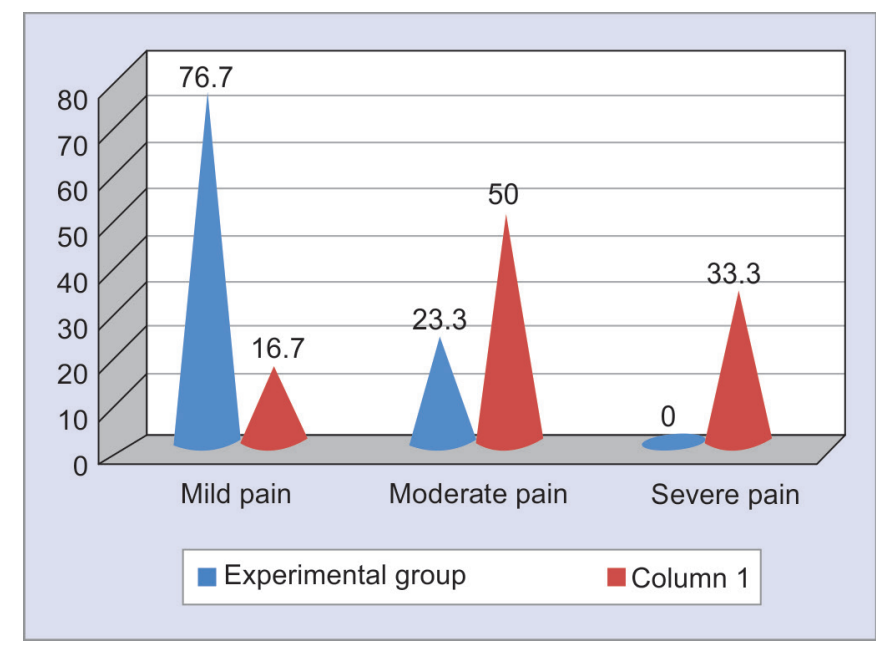

Fig. 2: Distribution of postcesarean mothers according to posttest score on level of pain in experimental and control groups

had experienced moderate pain. On the contrary, in the control group, $16.7 \%$ of the postcesarean mothers had experienced mild pain, about $50 \%$ had moderate pain, and $33.3 \%$ of the mothers had experienced severe pain as it is shown in Figure 2.

Majority (66.6\%) of the postcesarean mothers had mild stress, $30 \%$ of them had moderate stress, and $3.3 \%$ had severe stress. In the control group, $36.6 \%$ of mothers had mild stress, $46.6 \%$ of the mothers had moderate stress, and $16.7 \%$ of the mothers had severe stress as it is shown in Figure 3.

\section{Section D-Effectiveness of Benson's Relaxation Therapy on Stress and Pain among Postcesarean Mothers}

\section{Comparison between the Pretest and Posttest Scores on Level} of Pain in Experimental and Control Groups

There is a significant difference in pain within the groups, within experimental group, mean and SD of pretest pain and posttest pain were $4.367 \pm 1.326, t$-value is 18.041 , and $p$-value is 0.000 which is significant at the level of $<0.05$. In the control group, mean and SD 


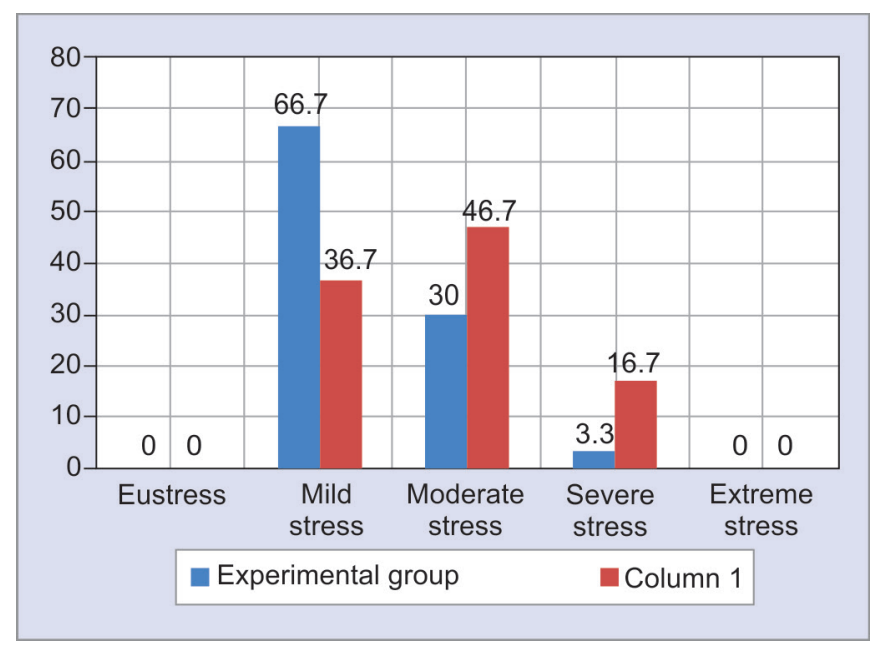

Fig. 3: Distribution of postcesarean mothers according to posttest score on the level of stress in experimental and control groups

of pretest pain and posttest pain were $2.400 \pm 1.831, t$-value is 7.180 , and $p$-value is 0.000 which is also significant at the level of $<0.05$.

\section{Comparison between the Pretest and Posttest Score on Level of Stress in Experimental and Control Groups}

Table 1 depicts the significant difference in stress within the groups. In experimental group, mean and SD of prestress and poststress were $17.476 \pm 15.937, t$-value is 6.003 , and $p$-value is 0.000 There was statistical significance with the $p$-value $<0.05$. In the control group, mean and SD of prestress and poststress were $2.233 \pm 10.683, t$-value is 1.145 , and $p$-value is 0.262 which is not statistically significant at the level of $>0.05$.

\section{Discussion}

In modern practice, with the objective of safe motherhood and mother-baby package program, the aim of obstetricians is to achieve a healthy mother and healthy baby. To achieve this goal, the cesarean section plays a vital role and the increasing trend of cesarean section is also related to it to a certain extent. ${ }^{9}$ Cesarean section is the most frequently performed surgery worldwide. ${ }^{10}$

The incidence of cesarean section is increasing in India as well as in Kerala. The pain and stress presented after a cesarean section makes the recovery difficult and delays the mother's contact with the newborns. It can also cause fatigue, mood swings, body image changes, and assumption of the parenteral role. Benson's relaxation therapy is a simple practice that one can learn to take 10 to 20 minutes a day and can help to relieve pain and stress.

Among the 60 postcesarean mothers, majority (41.7\%) were in the age-group of 30 and above years, and $66.7 \%$ were graduates. Most of them (70\%) were housewives and $50 \%$ are from a nuclear family. About $71.7 \%$ of mothers were living in an urban area and most of them (91.7) have not undergone any yoga classes.

The present study shows that while considering pretest pain, in the experimental group majority of postcesarean mothers $66.7 \%$ had experienced severe pain and about $33.3 \%$ of the postcesarean mothers had moderate pain, whereas in the control group, majority (73.3\%) of the postcesarean mothers had experienced severe and $26.7 \%$ had moderate pain, respectively. When considering
Table 1: Mean, SD, and $t$ value on level of stress among experimental and control groups

\begin{tabular}{lccccc}
\hline Groups & Mean & SD & t value & $d f$ & Sig. (two-tailed) \\
\hline $\begin{array}{l}\text { Prelevel and } \\
\text { postlevel of stress } \\
\text { among } \\
\text { experimental } \\
\text { group }\end{array}$ & 17.467 & 15.937 & 6.003 & 29 & 0.000 \\
$\begin{array}{l}\text { Prelevel and } \\
\text { postlevel of stress } \\
\text { among control }\end{array}$ & & & & & \\
group & 2.233 & 10.683 & 1.145 & 29 & 0.262 \\
\hline
\end{tabular}

posttest pain, in the experimental group, majority (76.7\%) of the postcesarean mothers had experienced mild pain and about $23.3 \%$ of them had experienced moderate pain. On the contrary, in the control group, $16.7 \%$ of the postcesarean mothers had experienced mild pain, about $50 \%$ had moderate pain, and $33.3 \%$ of the mothers had experienced severe pain.

In the experimental group, $16.3 \%$ had experienced severe pretest stress, about $53.3 \%$ of the mothers had moderate stress, and $33.3 \%$ had mild stress; none of them had eustress and extreme stress. In the control group, $16.7 \%$ of the postcesarean mothers had experienced severe stress, $46.7 \%$ had moderate stress, and $36.7 \%$ had mild stress. In control group also, none of them had eustress and extreme stress. In posttest stress among experimental group majority (66.6\%) of the postcesarean mothers had mild stress, $30 \%$ of them had moderate stress, and $3.3 \%$ had severe stress. On the contrary, in the control group, $36.6 \%$ of mothers had mild stress, $46.6 \%$ of the mothers had moderate stress, and $16.7 \%$ of the mothers had severe stress.

An experimental study was conducted to evaluate the effectiveness of Benson's relaxation therapy on reduction of pain and stress among postcesarean mothers admitted at a selected hospital, Pudukkottai; the objective was to assess the level of pain and stress among postcesarean mothers before intervention in both experimental group and control groups. The study reveals that among postcesarean mothers in the experimental group during pretest, $26.66 \%$ of them had moderate pain, and $73.33 \%$ of them had severe pain. During posttest, $93.33 \%$ of them had mild pain, and $6.66 \%$ of them had moderate pain. On the contrary, in the control group during pretest, $23.33 \%$ of them had moderate pain, and $76.66 \%$ of them had severe pain. During posttest, $60 \%$ of them had mild pain, $33.33 \%$ of them had moderate pain, and $6.66 \%$ of them had severe pain. In the experimental group during pretest, $66.66 \%$ of them had moderate stress, and $33.33 \%$ of them had severe stress. During posttest, $90 \%$ of them had mild stress, and $10 \%$ of them had moderate stress. On the contrary, in the control group during pretest, $73.33 \%$ of them had moderate stress, and $26.66 \%$ of them had severe stress. During posttest, $66.66 \%$ of them had mild stress, $26.66 \%$ of them had moderate stress, and $6.66 \%$ of them had severe stress.

Present study reveals a significant difference between pretest and posttest stress and pain in the experimental group, which is statistically significant with $p$-value $<0.05$. In the control group, there is no significant difference in pretest stress and posttest stress and there is a significant difference in pretest pain and posttest pain (significant at the level of $<0.05$ ). Majority of experimental group (76.7\%) had mild pain and $23.3 \%$ of them had moderate pain. 
On the contrary, in the control group, only $16.7 \%$ of the postcesarean mothers had mild pain and about $50 \%$ had moderate pain and $33.3 \%$ had severe pain.

\section{ConCLUSION}

The study concluded that the study participants got benefited from Benson's relaxation therapy on reduction of postcesarean pain and stress among mothers. Nurses play a significant role in preventing or reducing pain and stress among postcesarean mothers. This relaxation technique can apply in postnatal antenatal mothers for reducing their stress.

\section{References}

1. Annamma J. A comprehensive textbook of midwifery and gynaecological nursing. Edisi ke. 2012. p. 3.

2. Alhani $F$, Shad $H$, Anoosheh $M$, et al. The effect of programmed distraction on the pain caused by venipuncture among adolescents on hemodialysis. Pain Manag Nurs 2010;11(2):85-91. DOI: 10.1016/ j.pmn.2009.03.005.

3. Kwekkeboom KL, Cherwin CH, Lee JW, et al. Mind-body treatments for the pain-fatigue-sleep disturbance symptom cluster in persons with cancer. J Pain Symptom Manage 2010;39(1):126-138. DOI: 10.1016/ j.jpainsymman.2009.05.022.

4. Mathew RM, Mg S. Perceived postpartum stress and coping strategies among postnatal mothers at aims, Kochi. Asian J Pharm Clin Res
2017;10(12):116. DOI: 10.22159/ajpcr.2017.v10i12.21257. Available from: https://innovareacademics.in/journals/index.php/ajpcr/article/ view/21257.

5. Babu AR, Aswathy Sreedevi AJ, Krishnapillai V. Prevalence and determinants of somatization and anxiety among adult women in an urban population in Kerala. Indian J Commun Med 2019;44 (Suppl. 1):S66. DOI: 10.4103/ijcm.IJCM_55_19.

6. Jayaseelan J, Mohan MP. Coping strategies used by postnatal mothers with perceived stress. Indian J Psychiatry 2020;62(4):451. DOI: 10.4103/ psychiatry.IndianJPsychiatry_373_19.

7. Paramban S, Bala S, Sowmya JK, et al. Effectiveness of Benson's relaxation therapy on reduction of stress among primigravid mothers. Acta Med Int 2016;3(2):133. DOI: 10.5530/ ami.2016.2.27.

8. Johny SA, Moly KT, Sreedevi PA, et al. Effectiveness of nursing process based clinical practice guideline on quality of nursing care among post CABG patients. Int J Nurs Educ 2017;9(2):120-126. DOI: 10.5958/0974-9357.2017.00048.4

9. DSouza RJ, Narayani BH, Rao SB. Outcome of pregnancy with history of previous cesarean section. J South Asian Feder Obst Gynae 2017;9(4):308-311. DOI: 10.5005/jp-journals-10006-1519.

10. Babu J, Annie Annal M, Renuka K. Effectiveness of hand massage vs foot massage for pain in incision site among post-cesarean mothers admitted in obstetrical care units at Mahatma Gandhi Medical College and Research Institute, Puducherry. J South Asian Feder Obst Gynae 2019;12(3):70-73. DOI: 10.5005/ jp-journals-10084-12124. 